\title{
Production Magnesium Alloy Strip with Boss and Rib Section by Melt Drag Process and Experimental Conditions
}

\author{
Shinichi Nishida ${ }^{1,}$, Kazuki Fukudome ${ }^{1}$, J. Kudo ${ }^{1}$, M. Motomura ${ }^{2}$ \\ ${ }^{1}$ Waseda University, Faculty of Science and Engineering, Department of Applied Mechanical and \\ Aerospace Engineering, Motomura Lab., Assistant Professor, Okubo 3-4-1, Shinjuku-ku, Tokyo, \\ 169-0072, Japan \\ ${ }^{2}$ Waseda University, Faculty of Science and Engineering, Department of Applied Mechanical and \\ Aerospace Engineering, Professor, Okubo 3-4-1, Shinjuku-ku, Tokyo, 169-0072, and Kagami \\ Memorial Laboratory for Materials, Nishi-waseda, Shinjuku-ku, Tokyo, 169-0051, Japan \\ ashinichi-nishida@aoni.waseda.jp
}

Keywords: Magnesium alloy AZ31, strip casting, melt drag process, boss and rib

\begin{abstract}
This study aims to produce magnesium alloy strip with boss and rib directly from molten metal. Magnesium alloy is the lightest structural material, so it is expected to widely use for small electronic device and etc. We studied about melt drag process. Melt drag process is one of single roll strip casting process. We use model melt drag experimental device to produce rapid solidified magnesium strip with boss and rib. Substrate is used on model experimental device instead of roll to easily research shape of substrate. Diameter of boss is $5 \mathrm{~mm}, 7.5 \mathrm{~mm}$ and $10 \mathrm{~mm}$. Height of boss is 6 $\mathrm{mm}$. We revealed on this study that the experimental conditions to get good shape boss and rib, improvement substrate shape for good boss and rib, microstructure and etc..
\end{abstract}

\section{Introduction}

Magnesium alloy is the lightest structural material, so it is expected to widely use for small electronic device and etc.. And we studied about melt drag process [1]. Melt drag process is one of single roll strip casting process. We use model melt drag experimental device to produce rapid solidified magnesium strip with boss and rib. Model experimental device [2] has been designed for researching easily contacting conditions between molten metal and substrate of solidification roll.

Forming processes of boss and lib are such as press forging [3], die-casting and welding. However press forging needs big press machine for big load, die-casting limits kind of alloy, welding is difficult for magnesium. This study aims to produce magnesium alloy strip with boss and rib directly from molten metal. So boss and rib shapes were machined on substrate of model melt drag device. In first successful experimental conditions for producing boss and rib was researched. Next, solutions of problems like filling were revealed. And microstructure and crystal grain size was investigated.

\section{Experimental Procedure}

Model Experimental Device. Figure 1 shows the schematic illustrations of the model experimental device. Substrate substituted for the roll. So it is easy to change the factors of the substrate that is the roll in melt drag process, such as the material, roughness and surface finishing. In this study kinds of shapes of boss and rib were machined. This device is entirely covered. Since molten magnesium is very active, the device can be sealed up around the molten magnesium to fill the protective gases. The protective gases used inside the device are $\mathrm{CO}_{2}$ and OHFC-1234ze to prevent the burning of molten magnesium. 


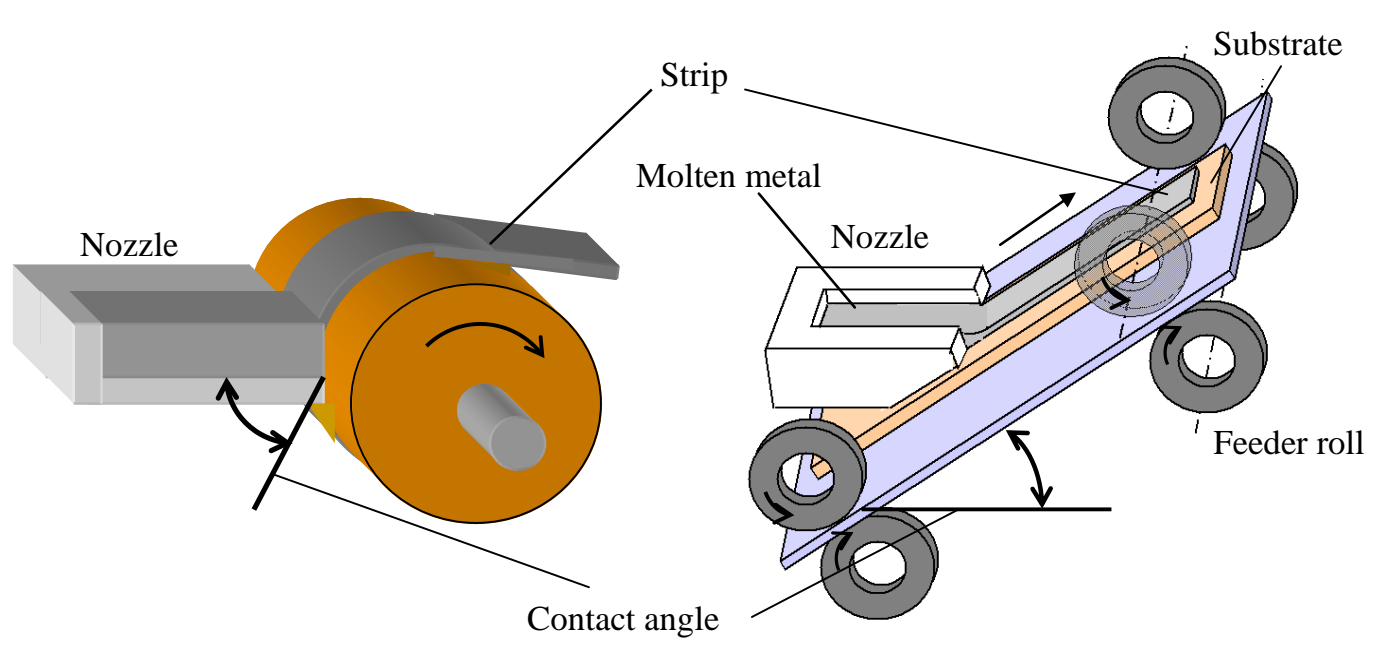

(a) Melt drag process

(b) This study (model experiment)

Fig.1 Schematic illustrations of melt drag process and model experiment device experiment)

Shapes and sizes of Boss and Rib. Figure 2 shows the schematic illustrations of objective boss and rib shapes of this study. Size of bosses are $\varphi 5 \sim 10 \mathrm{~mm}$, M10, height $6 \mathrm{~mm}$. Size of rib is width 3 $\mathrm{mm}$, length $30 \mathrm{~mm}$, height $3 \mathrm{~mm}$. Effect of casting direction for rib was investigated. Size of thick part for rigidity creation is width $30 \mathrm{~mm}$, height $3 \mathrm{~mm}$.

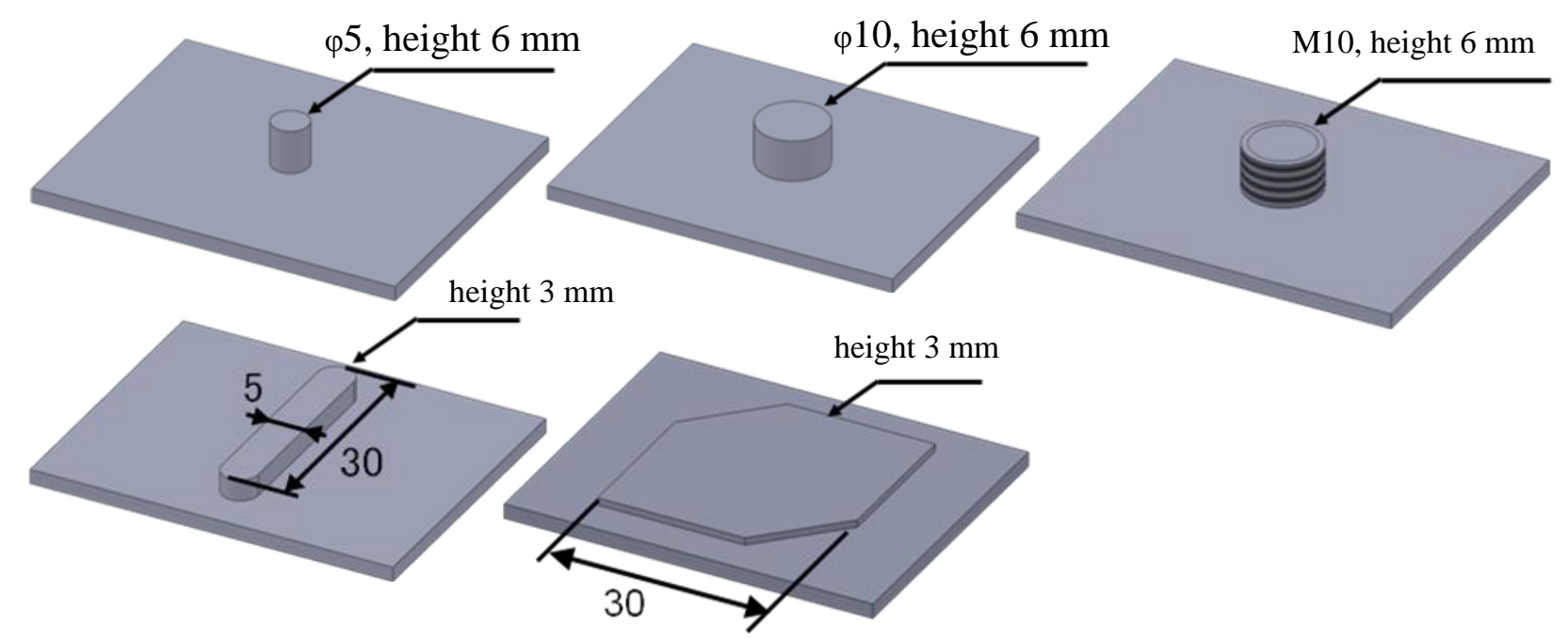

Fig.2 Schematic illustrations of objective shapes of bosses and ribs

Experimental conditions. Table 1 shows experimental conditions. Magnesium alloy is AZ31. Molten metal temperature is $750 \sim 840^{\circ} \mathrm{C}$. Substrate speed is $3 \sim 15 \mathrm{~m} / \mathrm{min}$. Molten metal height is length from bottom of nozzle, $40 \mathrm{~mm}$. Substrate material is $\mathrm{Cu}$. Contact angle is $40^{\circ}$. Substrate surface roughness is $\mathrm{Rz}_{\text {JIS }} 40 \mu \mathrm{m}$. These conditions were decided based on suitable conditions for producing strip without surface defects.

Table 1 Experimental Conditions

\begin{tabular}{c|c}
\hline Material & Magnesium alloy AZ31 \\
\hline Molten metal temperature ${ }^{\circ} \mathrm{C}$ & $750,780,810,840$ \\
\hline Substrate speed $\mathrm{m} / \mathrm{min}$ & $3,5,10,15$ \\
\hline Molten metal height mm & 40 \\
\hline Substrate material & $\mathrm{Cu}$ \\
\hline Contact angle $^{\circ}$ & 40 \\
\hline Substrate surface roughness Rz JIS $_{\text { }} \mu \mathrm{m}$ & 40 \\
\hline
\end{tabular}




\section{Results and Discussion}

Results of filling on boss $\phi \mathbf{1 0}$. Figure 3 shows results of substrate side filling on boss $\varphi 10$. Symbol $\circ$ means completely filling, $\Delta$ means corner filling-less and $\times$ means little filling. Figure 4 shows results of free solidified side dent depth. Figure 5 shows optimum experimental conditions. Over $840^{\circ} \mathrm{C}$ molten metal temperature, molten metal condition become bad and unstable. Substrate side filling is accomplished on high molten metal temperature and high substrate speed. Free solidified side filling is accomplished on high molten metal temperature and low substrate speed. Filling is affected on contacting time between molten metal and substrate in nozzle, and flowability of molten metal. So optimum experimental condition is decided; molten metal temperature $810^{\circ} \mathrm{C}$, substrate speed $5 \mathrm{~m} / \mathrm{min}$.
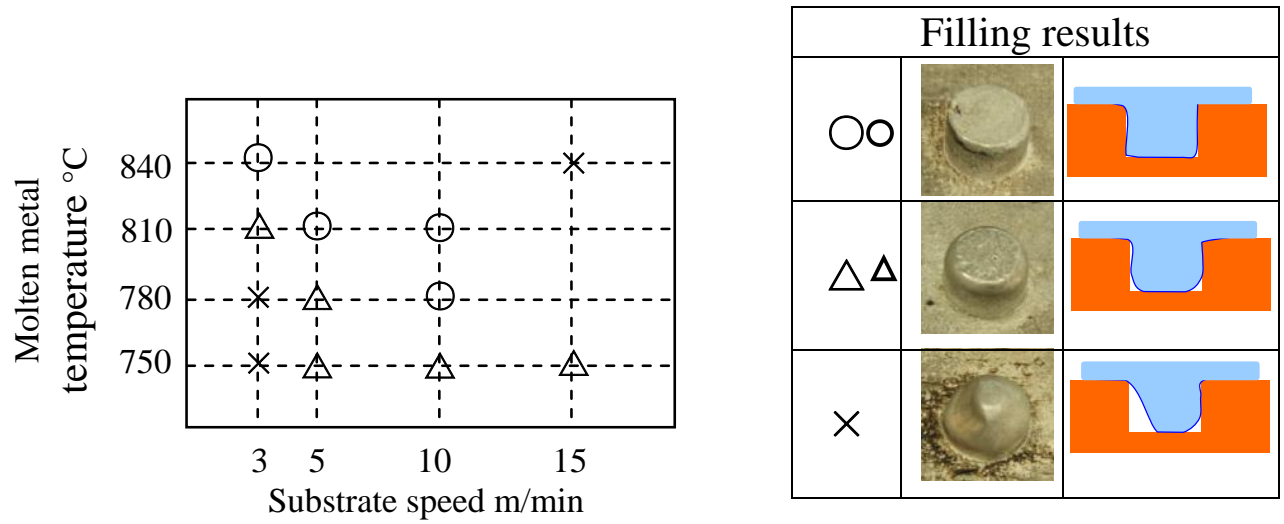

Fig.3 Results of substrate side filling on boss $\varphi 10$
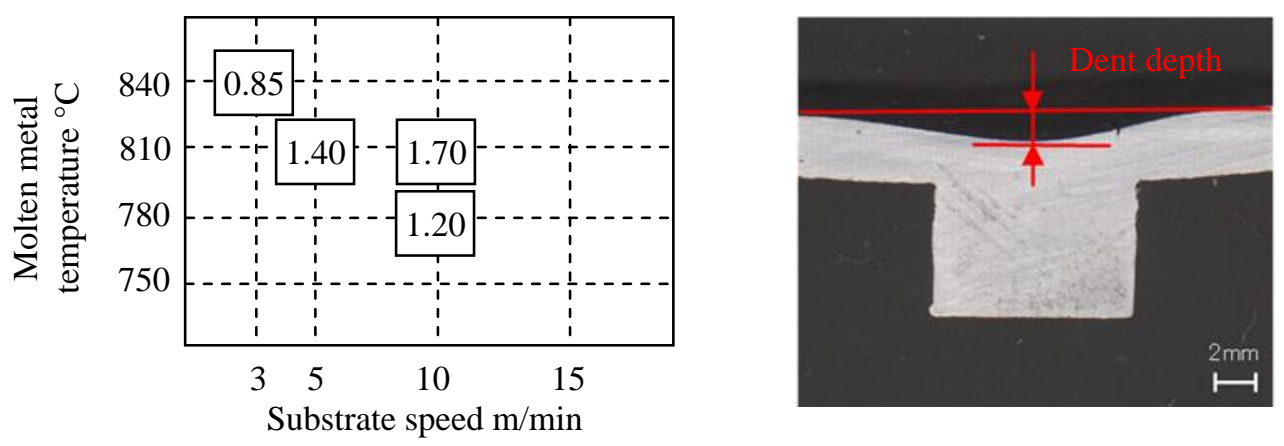

Fig.4 Results of free solidified side filling (dent depth) on boss $\varphi 10$

Other shapes results. Figure 6 shows all filling results. $\varphi 5$ boss was not filled. $\varphi 10$ boss was filled. M10 boss was not filled at corner. Rib of transverse direction was filled. Rib of casting direction was not filled at toe. Thick part was filled. To make an improvement of filling, it is effective to set the chamfer at substrate to get good flowability.

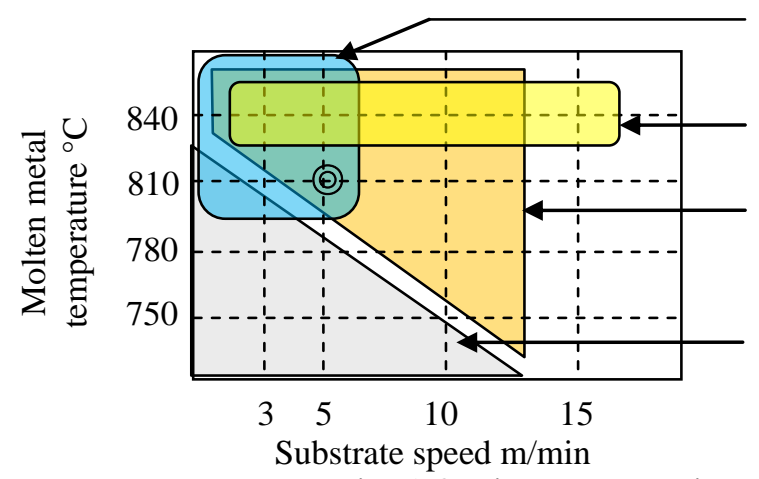

Good filling on free solidified side

Unstable molten metal

Good filling on substare side

Bad flowability and filling-less

Fig.5 Optimum experimental conditions 


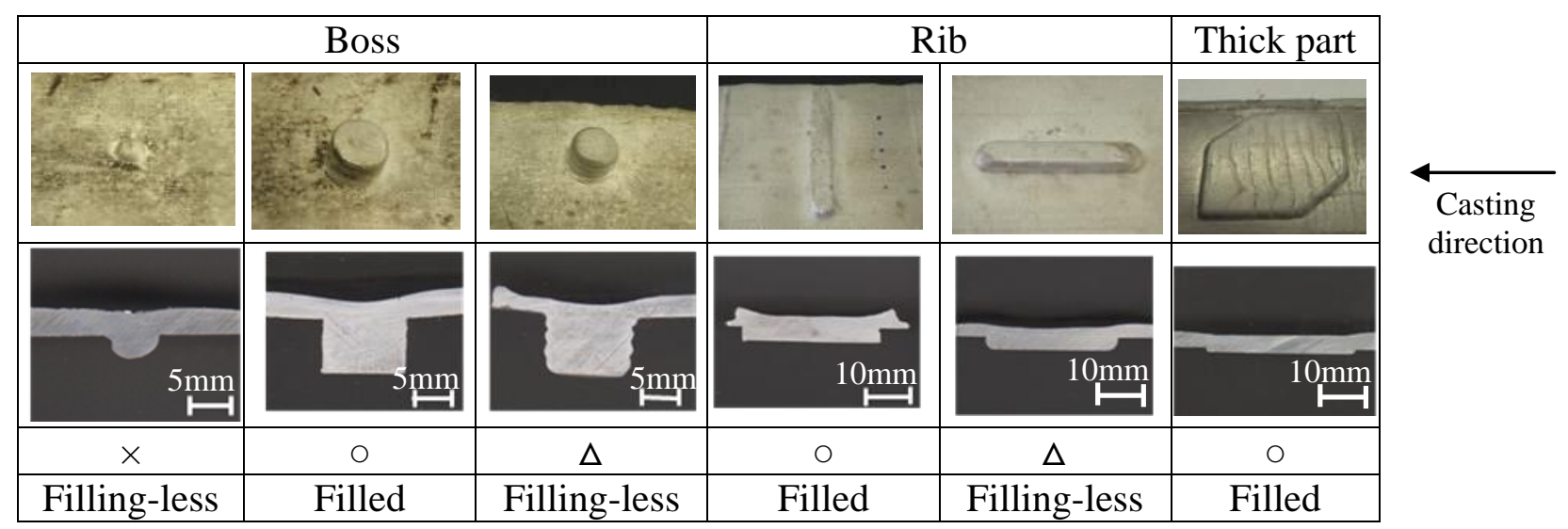

Fig.6 Shapes and filling trend

Microstructure. Figure 7 shows microstructure and crystal grain size. Crystal grain size is about $50 \sim 70 \mu \mathrm{m}$. Crystal grain is very refined by rapidly solidification and the shape is equiaxed crystal. The size become refining near substrate. Porosity was not observed.

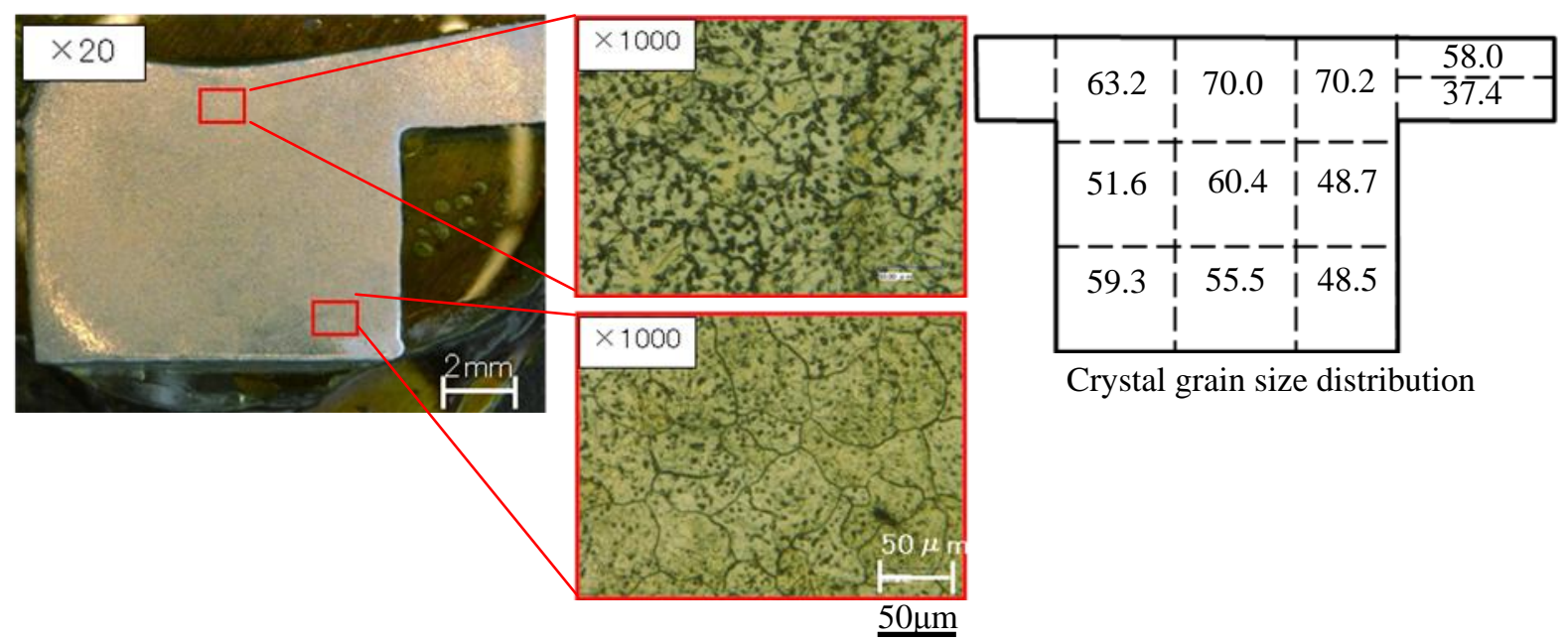

Fig.7 Microstructure and crystal grain size

\section{Summary}

Magnesium alloy strip with boss and rib directly from molten metal was succeeded. Optimum experimental conditions are molten metal temperature $780{ }^{\circ} \mathrm{C}$, substrate speed $5 \mathrm{~m} / \mathrm{min}$. Trend of filling at substrate side and free solidified side was revealed. Crystal grain size was about 50 70 $\mu \mathrm{m}$.

\section{References}

[1] S. Nishida et al.: The Journal of Japan Institute of Light Metals, 55(2005), p. 315-320

[2] S. Nishida et al.: 8th international conference on magnesium alloys, (2009), p. 431-436

[3] M. Shiraishi et al.: The Japan Society for Technology of Plasticity Hokuriku affiliate lecture collected papers, Vol. 18(2009), p.41-44 